\title{
ATIVIDADE ANTIBACTERIANA E A PREDITIVIDADE DO CONDIMENTO Artemisia dracunculus Linn. (Asteraceae), VARIEDADE inodora - ESTRAGÃO -, FRENTE À Salmonella sp. ${ }^{1}$
}

\author{
Heloisa Helena CARVALHO ${ }^{2, *}$, José Maria WIEST ${ }^{3}$, Dalton Palmeira GRECO ${ }^{4}$
}

\begin{abstract}
RESUMO
Avaliou-se a atividade antibacteriana de extrato aquoso do condimento estragão - Artemisia dracunculus linn. (Asteraceae), variedade inodora -, frente à Salmonella enteritidis (ATCC 11076), por meio do sistema de tubos múltiplos e pelo emprego de desinibidores bacterianos, determinando-se a Intensidade de Inibição/Inativação (IINIB/IINAB), observando-se expressiva inibição, bem como ausência de inativação sobre esta salmonela. Na presença do fator matéria orgânica/sujeira representada pelo leite, estes atributos repetiram-se, embora com menor intensidade de inibição. Posteriormente, avaliou-se a preditividade de uma técnica oficial de isolamento desta bactéria, utilizando uma solução experimental de leite e caldo BHI (Brain Heart Infusion), contaminada com $10^{4} \mathrm{UFC} / \mathrm{mL}$ da salmonela em estudo. Verificou-se a ausência de isolamento desta bactéria em alíquotas de $25 \mathrm{~mL}$, após períodos de 24, 48 e $72 \mathrm{~h}$ de incubação a $36^{\circ} \mathrm{C}$, comprometendo a Validade Preditiva dos Resultados Negativos (VPR-) do teste. Sugere-se que, nas investigações epidemiológicas de surtos toxiinfectivos alimentares, devem-se ser acrescidas informações sobre condimentação vegetal, entre outras, pertinentes à complexidade crescente do sistema de alimentação e nutrição.

Palavras-chave: atividade antibacteriana, Artemisia dracunculus, preditividade em salmonela, alimentos condimentados, estragão.
\end{abstract}

\section{SUMMARY}

ANTIMICROBIAL ACTIVITY AND PREDITIVITY OF Artemisia acunculus (Asteraceae), VAR. inodora - TARRAGON -, AS CONDIMENT, AGAINST Salmonella sp. It was evaluated antibacterial activity of watery extract of the condiment tarragon-Artemisia dracunculus linn., var. inodora -, against the Salmonella enteritidis (ATCC 11076), through the system of multiple pipes and the job of bacterial inhibitors, it was determined Intensity of inhibition/inativation (IINIB/IINAB), observing expressive inhibition, as well as absence of inativation on this salmonela. In presence of the organic substance, represented by skimmed barren milk, these attributes if had repeated, even so with lesser intensity of inhnibition. Later, it was evaluated preditividade of one official technique of isolation of this bacterium, using an experimental solution of milk and BHI broth (Brain Heart Infusion), contaminated with $10^{4} \mathrm{CFU} / \mathrm{mL}$ of salmonela in study. It was verified absence of isolation of this bacterium in aliquots of $25 \mathrm{~mL}$, after periods of 24,48 and 72 hours of incubation at $36^{\circ} \mathrm{C}$, compromising the Preditive Validity of the Negative Results (PVR-) of the test. One suggests that, in the inquiries epidemiologists of alimentary toxinfectives studies, information could be increased about vegetal condimentary, among others, pertinent to the increasing complexity of the system of feeding and nutrition.

Keyswords: antimicrobial activity, Artemisia dracunculus, preditivity in salmonella, condimented foods, tarragon.

\section{1 - INTRODUÇÃO}

Plantas aromáticas/condimentares, ou ainda as chamadas especiarias, usadas em alimentos com fins aromatizantes, tendo identificada a atividade antibacteriana, podem ser usadas como conservantes de alimentos [1]. Os consumidores têm buscado pelo consumo de alimentos de

\footnotetext{
${ }^{1}$ Recebido para publicação em 1/11/2004. Aceito para publicação em 23/1/2006 (001429)

${ }^{1}$ Artigo baseado na tese Avaliação da atividade antibacteriana de plantas com indicativo etnográfico condimentar, defendida pela $d r^{a}$. Heloisa Helena Carvalho, no dia 26 de fevereiro de 2004, no programa de pós-graduação em Ciências Veterinárias (PPGCV/UFRGS), sob a orientação do professordoutor José Maria Wiest

${ }^{2}$ Nutricionista - Universidade Federal do Rio Grande do Sul (UFRGS)

Avenida Bento Gonçalves, 9.500, prédio 43.212 (ICTA) - Bairro Agronomia - Porto Alegre (RS)

CEP 91540-000

Telefones: (51) 3316-7107 e 3316-6248. Fax: (51) 3316-7048

E-mail:hhccar@brturbo.com.br

${ }^{3}$ Docente e pesquisador - Universidade Federal do Rio Grande do Sul

${ }^{4}$ Acadêmico $-10^{\circ}$ semestre de Medicina Veterinária da Universidade Federal do Rio Grande do Sul (UFRGS)

*A quem a correspondência deve ser enviada
}

alta qualidade, preferencialmente os que não sejam extremamente processados e os mais naturais possíveis [18]. A indústria de alimentos tem passado por constantes pressões para que sejam removidos os conservantes químicos e que adotem alternativas naturais para a preservação do tempo de vida dos produtos alimentícios [27]. Entre estas alternativas encontram-se os Sistemas Antimicrobianos Naturais, resultantes de recursos renováveis.

O estragão utilizado como condimento/aromatizante na culinária internacional, destacou-se como efetivo inibidor frente a várias bactérias, principalmente Salmonella sp., em triagens de antimicrobianos naturais de origem vegetal [10]. A planta é originária do Oriente Médio, chegando à Europa no século XVI através da Espanha mourisca, condimentando desde grelhados até bebidas geladas [21]. São conhecidas duas espécies de estragão: o francês ou estragão verdadeiro, Artemisia dracunculus Linn., var. sativa, que não produz sementes e é reproduzido por estacas, não tolerando o excesso de luminosidade nem o excesso de chuvas. Dificilmente é encontrado nas condições brasileiras; e o estragão russo, Artemisia dracunculus, var. inodora, também conhecido como Artemisia dracunculoides, que produz sementes em abundância e é mais 
adaptado às nossas condições. Embora quase inodoro, desenvolve algum aroma com a idade, não tendo grande valor comercial. O emprego gastronômico do estragão é feito com parcimônia, por meio de diferentes extrações, em iguarias como vinagres aromatizados, saladas com foie gras, cremes, sopas e purês com leite e ovos [17].

O presente trabalho propõe avaliar a Intensidade de Atividade Inibição (IINIB) e a Intensidade de Atividade de Inativação (IINAB), seletivas, do condimento vegetal estragão, bem como avaliar a preditividade das pesquisas de salmonela em alimento experimental condimentado com esta especiaria.

\section{2 - MATERIAL E MÉTODOS}

\section{1 - Amostra vegetal}

Artemisia dracunculus Linn., var. inodora, estragão, foi colhido em Eldorado do Sul (RS), distrito de Parque Eldorado, no período de floração, de uma comunidade de exemplares com dez unidades, mantidos em floreira e classificados como introduzido na área [9].

Esta planta foi classificada botanicamente por MARODIN [19], providenciando-se exsicatas, desenvolvidas segundo MING [20], material este destinado ao depósito junto ao herbário do Instituto de Biociências, no Departamento de Botânica da UFRGS, Porto Alegre (RS), Brasil.

\section{2 - Extrato vegetal}

Talos, folhas e flores do estragão, verdes, foram trituradas grosseiramente e colocadas em álcool etílico, de cereais, a $96^{\circ} \mathrm{GL}$, segundo FARMACOPÉIA BRASILEIRA [16] na proporção de $400 \mathrm{~g}$ de planta verde para 1.000 $\mathrm{mL}$ de álcool, para extração hidro-alcoólica. Em um prazo não inferior a 15 dias, este extrato foi submetido à destilação fracionada sob pressão reduzida em rota-vapor, desprezando-se a porção alcoólica com re-hidratação asséptica, restabelecendo-se as concentrações iniciais do extrato vegetal, denominado então, de solução conservante ou antibacteriana.

\section{3 - O inóculo}

Salmonella entérica sorovar Enteritidis (ATCC 11076), mantida em banca de cultura estocado a $-18^{\circ} \mathrm{C}$, foi ativada em BHI (Brain Heart Infusion, OXOID), a $36^{\circ} \mathrm{C}$ por 18 a $24 \mathrm{~h}$ de incubação, atingido, no mínimo, $1,0 \times 10^{9} \mathrm{UFC} / \mathrm{mL}$, confrontada nos diferentes experimentos com o conservante vegetal por meio de diluições seriais logarítmicas/suspensões bacterianas, determinadas biometricamente segundo CAVALLI-SFORZA [12].

\section{4 - O método e as técnicas}

\subsection{1 - Método para avaliação antibacteriana}

O método para a avaliação da atividade antibacteriana do extrato de estragão foi o de diluição [14], usando-se na triagem a técnica do sistema de tubos múltiplos, confrontando a solução conservante de estragão, com 8 diluições $\left(10^{-1}\right.$ a $\left.10^{-8} \mathrm{UFC} / \mathrm{mL}\right)$ dos inóculos de salmonela [2, 3, 4]. Os resultados foram lidos como Intensidade da Atividade de Inibição Bacteriana (IINIB) e Intensidade da Atividade de Inativação Bacteriana (IINAB). Entende-se por IINIB o resultado do confronto da bactéria com a solução conservante, em meio BHI (Brain Heart Infusion, OXOID), por meio de leituras por plaqueamentos, independentes de crescimento/turvação em meio seletivo e diferencial (Mac Conkey, OXOID), em intervalos de 24, 48 e 72 h de incubação a $36^{\circ} \mathrm{C}$. Entende-se por IINAB o mesmo resultado, porém sob influência de desinibidores bacterianos acrescidos ao BHI [ $14 ; 15 ; 24 ; 25]$. IINIB e IINAB são representadas por variáveis ordinais arbitrárias que assumiram valores de 8 a 0 e que indicam a intensidade da atividade antibacteriana (ou não atividade $=$ n.a) que uma solução testada tem sobre uma dada dose infectante de microrganismo, nas diferentes condições do experimento, ou seja, com e sem desinibidores bacterianos.

\subsection{2 - Preditividade IINIB E IINAB}

A leitura dos resultados IINIB e IINAB foi submetida à avaliação de Sensibilidade (S) e a Validade Preditiva dos Resultados Positivos (VPR+). A Especificidade (E) e a Validade Preditiva dos Resultados Negativos (VPR-) foram garantidas pelo emprego de desinibidores bacterianos. A precisão do método (influência de fatores extrínsecos) foi testada pela alternância de executores buscando semelhança e significância estatística dos resultados conseqüentes [28, 13].

\subsection{3 - Simulação em alimentos}

Seguindo os objetivos, simulou-se, experimentalmente, alimento condimentado com solução conservante de estragão a 50\%, a partir de droga crua, segundo FARMACOPÉIA BRASILEIRA [16], utilizando BHI em concentração de uso acrescido de $20 \%$ de leite desnatado esterilizado representando o fator matéria orgânica/sujeira. Esta simulação foi contaminada com salmonela na dose infectante de $10^{4} \mathrm{UFC} / \mathrm{mL}$. ou diluição de $10^{-5}$ de um inóculo de 2,3 x $10^{9} \mathrm{UFC} / \mathrm{mL}$. Elegeu-se a suspensão de $10^{4} \mathrm{UFC} / \mathrm{mL}$ como inóculo experimental, uma vez que Carvalho [11] confirmou, à luz de outros autores que em relação a bactérias deteriorantes em carnes frescas, a dose inicial para o aparecimento de sintomas de deterioração encontra-se $10^{3}$ a $10^{4} \mathrm{UFC} / \mathrm{g}$. O experimento foi submetido, em duas repetições, à pesquisa de salmonela segundo a técnica oficial do Ministério de Agricultura, Pecuária e Abastecimento Mapa, do Brasil [6].

\subsection{4 - Análise estatística}

Na verificação matemática dos resultados obtidos as variáveis IINIB e IINAB foram avaliadas através da análise estatística descritiva e análise de variância através do teste de Fischer [12]. 


\section{3 - RESULTADOS E DISCUSSÃO}

Observando a Tabela 1, a solução conservante de estragão na concentração 50\% frente ao inóculo de salmonela em estudo mostrou intensa inibição (IINIB) em ambas as análises, ressaltando que estas foram executadas por diferentes técnicos, a partir de alcolaturas com plantas de diferentes coletas. Isto sugere precisão do método (resistência a fatores extrínsecos), pela diferença não significativa a nível de 5\% (teste de Fisher) dos resultados obtidos.

TABELA 1 - Intensidade de Inibição e Inativação (IINIB-IINAB) produzidos por extrato aquoso a $50 \%$ de estragão (Artemísia dracunculus linn., var. inodora), sobre Salmonella entérica sorovar enteritidis (ATCC 11076)

\begin{tabular}{|c|c|c|c|c|c|c|}
\hline \multirow[b]{3}{*}{ Tempo } & \multicolumn{6}{|c|}{ Estragão a $\mathbf{5 0 \%}$} \\
\hline & \multicolumn{3}{|c|}{ IINIB } & \multicolumn{3}{|c|}{ IINAB } \\
\hline & $\begin{array}{c}1^{\mathrm{a}} \\
\text { análise* }\end{array}$ & $\begin{array}{c}2^{a} \\
\text { análise }^{*}\end{array}$ & Média & $\begin{array}{c}1^{\mathrm{a}} \\
\text { análise* }^{*}\end{array}$ & $\begin{array}{c}2^{a} \\
\text { análise* }\end{array}$ & Média \\
\hline $24 \mathrm{~h}$ & 8 & 6 & 7 & 0 & 0 & 0 \\
\hline $48 \mathrm{~h}$ & 7 & 6 & 6,5 & 0 & 0 & 0 \\
\hline $72 \mathrm{~h}$ & 8 & 8 & 8 & 0 & 0 & 0 \\
\hline
\end{tabular}

8 a 1 =variáveis ordinais arbitrárias, decrescentes, que representam a Intensidade de Inibição/latência (IINIB) ou Inativação/morte (IINAB). * Média de duas execuções. $0=$ não atividade

Pela mesma tabela, deduz-se que não houve inativação/morte bacteriana (IINAB) mesmo após $72 \mathrm{~h}$ de exposição do inóculo à solução conservante, resultado garantido pelo emprego dos desinibidores bacterianos. Por outro lado, como os resultados de IINAB foram zero de intensidade, isto é, ocorreu crescimento bacteriana pleno e, nas colunas IINIB, obteve-se resultados expressivos de intensidade de inibição. Entende-se que a salmonela esteja somente em estado de latência (inibição) sob o efeito da solução conservante de estragão, o que pôde ser revertido pelos desinibidores.

Na Tabela 2, com a introdução do fator matéria orgânica/sujeira, verificaram-se resultados semelhantes aos já discutidos na Tabela 1, embora com menor intensidade do que o IINIB. Este fato pode ser atribuído à própria matéria orgânica/sujeira presente, representada pelo leite desnatado. Pode-se destacar, novamente, a IINAB zero da

TABELA 2 - Intensidade de Inibição e Inativação (IINIB - IINAB) produzidos por extrato aquoso de estragão (Artemísia dracunculus linn., var. inodora) a 50\%, sobre Salmonella entérica sorovar enteritidis (ATCC 11076), na presença de 20\% de matéria orgânica/sujeira (leite desnatado esterilizado)

\begin{tabular}{|c|c|c|c|c|c|c|}
\hline \multirow[b]{3}{*}{ Tempo } & \multicolumn{6}{|c|}{ Estragão a $\mathbf{5 0 \%}$} \\
\hline & \multicolumn{3}{|c|}{ IINIB } & \multicolumn{3}{|c|}{ IINAB } \\
\hline & $\begin{array}{c}1^{a} \\
\text { análise* }^{*}\end{array}$ & $\begin{array}{c}\mathbf{2}^{\mathbf{a}} \\
\text { análise* }^{*}\end{array}$ & Média & $\begin{array}{c}1^{\mathrm{a}} \\
\text { análise* }^{*}\end{array}$ & $\begin{array}{c}2^{\mathbf{a}} \\
\text { análise* }^{*}\end{array}$ & Média \\
\hline $24 \mathrm{~h}$ & 1 & 4 & 2,5 & 0 & 0 & 0 \\
\hline $48 \mathrm{~h}$ & 1 & 3 & 2 & 0 & 0 & 0 \\
\hline $72 \mathrm{~h}$ & 1 & 0 & 0,5 & 0 & 0 & 0 \\
\hline
\end{tabular}

8 a $1=$ variáveis ordinais arbitrárias, decrescentes, que representam a Intensidade de inibição/latência (IINIB) ou inativação/morte (IINAB). *Média de duas execuções. $0=$ não atividade solução conservante de estragão em estudo. A hipótese para a diferença da IINIB entre as duas análises seria que a solução conservante de estragão originou-se de alcolaturas de plantas coletadas com floração em épocas diferentes, embora da mesma comunidade de plantas. Outros fatores, como forma de extração dos princípios ativos; teores de umidade da planta e mesmo influências dos próprios microrganismos em teste poderiam ainda ser considerados, segundo SKINNER [26], como atributos intervenientes nas observações presentes.

A pesquisa de salmonela, neste alimento, seguindo metodologia oficial, indicou a ausência da mesma, nas análises efetuadas nos diferentes tempos de incubação, exceto após $72 \mathrm{~h}$ em uma das repetições (Tabela 3).

TABELA 3 - Pesquisa (presença ou ausência) em repetições independentes, segundo técnica oficial do MAPA, Brasil, de Salmonella entérica sorovar enteritidis (ATCC 11076), em alimento experimentalmente simulado (BHI+leite desnatado) condimentado por extrato de estragão a $50 \%$ da droga crua, em diferentes intervalos de incubação a $36^{\circ} \mathrm{C}$

\begin{tabular}{lcc}
\hline \multirow{2}{*}{ Intervalos de repetição } & \multicolumn{2}{c}{ Pesquisa de Salmonella ssp. (MAPA) } \\
\cline { 2 - 3 } & $\mathbf{1}^{\text {a }}$ análise & $\mathbf{2}^{\mathrm{a}}$ análise \\
\hline $24 \mathrm{~h}$ & Ausência & Ausência \\
$48 \mathrm{~h}$ & Ausência & Ausência \\
$72 \mathrm{~h}$ & Presença & Ausência \\
\hline
\end{tabular}

Embora BOARD [5] afirme serem necessárias $10^{5} \mathrm{UFC} / \mathrm{g}$ de Salmonela spp. no alimento ingerido para produzir uma enfermidade toxiinfectiva em uma pessoa sensível, as normas vigentes [7], determinam a ausência de Salmonela spp. em 25 g de alimento, sendo plausível ter-se utilizado doses infectantes de inóculo a $10^{4} \mathrm{UFC} / \mathrm{mL}$.

Considerando as Tabelas 1 e 2, verifica-se que a salmonela sofre inibição frente à solução conservante de estragão, fato garantido pela presença e ausência dos desinibidores bacterianos introduzidos no experimento, poder-se-ia deduzir que, frente ao alimento simulado, a salmonela ainda esteja sob influência do condimento estragão, isto é, em inibição, e que esta pesquisa de salmonela, não esteja conseguindo desinibir a bactéria, prejudicando a preditividade dos resultados negativos observados, devendo ser interpretado como resultado falso-negativo.

A confirmação, já referida, da presença (isolamento positivo/resultados positivos verdadeiros) às $72 \mathrm{~h}$ em uma das repetições, poderia ser atribuída, hipoteticamente, à degradação do(s) elemento(s) do fitocomplexo(s) antibacteriano(s) responsável pela inibição, presente no extrato/droga crua do estragão em estudo com solução conservante.

Reforçando estas considerações, PINTO [22], analisando os registros de enfermidades bacterianas transmitidas por alimentos entre 1988 e 1997, no Rio Grande do Sul, constatou que $33,63 \%$ dos surtos foram causados por Salmonella spp. e que, por outro lado, em 38,22\% dos surtos não foi possível identificar o agente causador. 
As diretrizes estabelecidas pela WORLD HEALTH ORGANIZATION [29], por BRYAN et al. [8] e retomadas por PINTO e BERGMANN [23], enfatizam a necessidade da investigação epidemiológica em casos de surtos toxiinfectivos alimentares, atendendo a história clínica (sinais, sintomas, alimentos ingeridos, atividade das pessoas envolvidas, período de incubação e outras informações pertinentes), obtidos por entrevista de todos os envolvidos no surto, independente de se apresentarem doentes ou não, abrangendo recordatório alimentar das últimas $72 \mathrm{~h}$ anteriores ao aparecimento dos sintomas.

Os autores recomendam também a coleta de amostras para isolamento do agente causal (fezes, sangue, urina, conteúdo gástrico/vômito ou lavagem bem como de alimentos envolvidos segundo sua taxa de ataque, devendo ser registradas as condições de armazenamento na hora da coleta). Embora os relatos afirmem $[22 ; 23]$ que a maioria dos surtos foram residenciais $(28,64 \%)$ e no comércio de alimentos prontos (26,73\%), na investigação epidemiológica nenhuma informação é solicitada, mormente nas condições domiciliares e de consumo comercial, quanto à condimentação, aromatização, técnicas de pré-preparo e preparação, de gastronomia étnica, entre outros possíveis fatores intervenientes nos resultados de pesquisa de agentes causais toxiinfectivos.

\section{4 - CONCLUSÕES}

O extrato aquoso (droga crua a 50\%), reconstituído na relação peso-volume inicial, de Artemisia dracunculus linn., var. inodora, (Asteraceae), “estragão”, apresentou Intensidade de Atividade de Inibição Bacteriana (IINIB) significativa frente à Salmonella entérica sorovar enteritidis (ATCC 11076), não apresentando Atividade de Inativação Bacteriana (IINAB) frente a esta bactéria, nas mesmas condições de experimento.

As observações repetiram-se, embora em menor intensidade, quando introduziu-se o fator matéria orgânica/sujeira, representado por leite desnatado esterilizado.

Em alimento experimentalmente simulado à base de leite, condimentado por solução conservante de estragão a $50 \%$, contaminado por $10^{4} \mathrm{UFC} / \mathrm{mL}$ de Salmonella entérica sorovar enteritidis (ATCC 11076), observou-se o atributo ausência, quando da pesquisa deste agente, segundo técnicas regulamentares.

Extratos vegetais, no modelo "estragão", podem ser inibidores bacterianos, interferindo na Validade Preditiva dos Resultados Negativos (VPR-) e na especificidade de pesquisa de salmonela em alimentos.

$\mathrm{Na}$ investigação epidemiológica de surtos toxiinfectivos alimentares, poderiam ser acrescidas mais informações sobre condimentação, aromatização, práticas de pré-preparo e preparo, de gastronomia étnica, entre outras, pertinentes à complexidade crescente do sistema de alimentação e nutrição.

\section{5 - REFERÊNCIAS BIBLIOGRÁFICAS}

[1] AURELI, P.; COSTATINI, A.; ZOLEA, S. Antimicrobial activity of essential oils Listeria monocytogenes. J. Food Protection, Iowa, v. 55, n. 5, p. 344-348, 1992.

[2] AVANCINI, C.A.M. Desinfecção em saúde e produção animal: bacteriostasia e bactericidia de Bacharis trimera (less.) D. L. - Compositae (carqueja), frente a microorganismos entéricos e cutâneos. Porto Alegre, 101 p. Dissertação (mestrado em Ciências Veterinárias), Faculdade de Medicina Veterinária. Universidade Federal do Rio Grande do Sul (UFRGS). 1995.

[3] AVANCINI, C.A.M. Saneamento aplicado em saúde e produção animal: etnografia, triagem da atividade antibacteriana de plantas nativas no sul do Brasil e testes de avaliação do decocto de Hypericum caprifoliatum cham. e Schlecht - Hypericaceae (Guttiferae) - ("escadinha"/"sinapismo") para uso como desinfetante e anti-séptico. Porto Alegre, 309 p. Tese (doutorado em Ciências Veterinárias), Faculdade de Medicina Veterinária. Universidade Federal do Rio Grande do Sul (UFRGS). 2002.

[4] AVANCINI, C.A.M,; WIEST, J.M.; IRGANG, B.E.; ALMEIDA, J.P.; MUNDSTOCK, E.C. Atividade antibacteriana in vitro do decocto de Hypericum caprifoliatum Cham. e Schlecht. - Hypericaceae (Guttiferae) - ("escadinha"/ "sinapismo") sobre bactérias de interesse em ambientes na área de medicina veterinária. Ars. Vet., Jaboticabal, v. 18, n. 3, p. 300-306, 2002.

[5] BOARD, R.G. Introducción a la microbiologia moderna de los alimentos. Zaragoza: Acribia, 1988.

[6] BRASIL. MINISTÉRIO DA AGRICULTURA PECUÁRIA E ABASTECIMENTO. SECRETARIA DE DEFESA AGROPECUÁRIA. Instrução Normativa n ${ }^{\circ} 62$ (26 ago. 2003). Métodos analíticos oficiais para análises microbiológicas para controle de produtos de origem animal e água. Diário Oficial da União (28 set. 2003). Disponível em: http://extranet.agricultura.gov.br/agrolegis/do/consultaLei?op=viewTextual\&codigo $=2851$. Acesso em 22 jan. 2004.

[7] BRASIL. MINISTÉRIO DA SAÚDE. AGÊNCIA NACIONAL DE VIGILÂNCIA SANITÁRIA. RDC nº 12 (3 jan. 2001). Regulamento técnico sobre padrões microbiológicos para alimentos. Disponível em: http://www.anvisa. gov.br/legisl/resol/12 01rdc.htm. Acesso em: 26 jan. 2004.

[8] BRYAN, F.L.; ANDERSON, H.W.; COOK, O.D.; GUZENVICH, J.; LEWIS, K.H.; SWANSON, R.C.; TODD, E.C.D. Procedures to investigate foodborne illness. $4^{\text {th }}$ ed., Iowa: International Association of Milk, Food and Envirommental Sanitarians, 1987.

[9] CARVALHO, D.A.; VILELA, E.A.; OLIVEIRA, A.T. Plantas herbáceas e subarbustos ocorrentes na região do alto Rio Grande (MG), com potencial para revegetação em áreas de depleção de reservatórios de hidrelétricas. Ciênc. Agrotéc., Lavras, v. 21, n. 2, p. 182-188, 1997.

[10] CARVALHO, H.H.C. Avaliação da atividade antibacteriana de plantas com indicativo etnográfico condimentar sobre contaminantes e inóculos padronizados. Porto Alegre, 200 p. Tese (doutorado em Ciências Veterinárias), Faculdade de Medicina Veterinária. Universidade Federal do Rio Grande do Sul (UFRGS). 2004,

[11] CARVALHO, H.H.C. Efeito do uso de glutamato monossódico na incidência e deterioração de carnes cruas e mortadela por Brochothrix thermosphacta. Porto Alegre, 104 p. Dissertação (mestrado em 
Microbiologia Agrícola e do Ambiente), Faculdade de Agronomia. Universidade Federal do Rio Grande do Sul (UFRGS). 1997,

[12] CAVALLI-SFORZA, L. Biometrie. Stuttgart, Gustav Fisher V., 1974.

[13] CÕRTES, J A. Epidemiologia: conceitos e princípios fundamentais. São Paulo, Varela, 1993.

[14] DEUTSCHE GESELLSCHAFT FÜR HYGIENE UND MIKROBIOLOGIE (Sociedade Alemã de Higiene e Microbiologia) Richtlinien für die prüfung chemischer desinfektionsmittel (Normas para a testagem de desinfetantes químicos). In: BORNEFF J. Zblt. Bakt. Hyg., I Abteilung, Originale B. Stuttgart, G.Thieme Verlag, p. 397-411; 1977.

[15] DEUTSCHE VETERINÄRMEDIZINISCHE GESELLSCHAFT (Sociedade Alemã de Medicina Veterinária). Richtlinien zur prüfung chemischer desinfektionsmittel für die veterinärmedizin (Normas para a testagem de desinfetantes químicos para a Medicina Veterinária). In: SCHLIESSER, Th.; Strauch D. Desinfektion in Tierhaltung, Fleisch - und Milschwirtschaf. Stuttgart, Enke Verlag, p. 47-55, 1981.

[16] FARMACOPÉIA DOS ESTADOS UNIDOS DO BRASIL. $2^{\mathrm{a}}$ ed., São Paulo, Siqueira, 1959.

[17] GIACOMETTI, D.C. Ervas condimentares e especiarias. São Paulo, Nobel, 1989.

[18] GOULD, G.W. Industry perspective on the use of natural antimicrobials and inhibitors for food applications. J. Food Protection, Iowa, v. 58, n. 1, p. 82-86, 1995.

[19] MARODIN, S. Identificação botânica das espécies condimentares: utilizadas no projeto produtos lácteos condimentados, atividade antibacteriana de condimentos vegetais sobre contaminantes e inóculos padronizados. Porto Alegre, 8 p. Relatório Técnico (CNPq $n^{\circ}$ 523193). Instituto de Ciência e Tecnologia de Alimentos. Universidade Federal do Rio Grande do Sul (UFRGS), 2004.

[20] MING, L.C. Coleta de plantas medicinais. In: DISTASI L.C. Plantas medicinais: arte e ciência. Um guia para o estudo interdisciplinar. São Paulo, Editora Unesp, 1996, p. 69-86.
[21] NORMAN, J. Aromatic herbs. Toronto, Bantan Books, 1990.

[22] PINTO, A.T. Investigação de enfermidades transmitidas por alimentos. Porto Alegre, 102 p. Dissertação (mestrado em Ciências Veterinárias), Faculdade de Medicina Veterinária. Universidade Federal do Rio Grande do Sul (UFRGS), 1999.

[23] PINTO, A.T.; BERGMANN, G.P. Investigação de enfermidades transmitidas por alimentos. Hig. Alim., São Paulo, v. 14, n. 74, p. 21-24, 2002.

[24] REYBROUCK, G. Efficacy of inactivators against 14 disinfectant substances. Zblt. Bakt. Hyg. I Abt. Orig. B., Stuttgart, v. 68A, p. 480-492, 1979.

[25] REYBROUCK, G. The testing of disinfectants. Int. Biodet. Biodeg., Oxford, v. 41, p. 269-272, 1998.

[26] SKINNER, F.A. Antibiotics. In: PAECH, K; TRACEY K. V. (Ed.). Moderne methoden der pflanzenanalyse: modern methods of plants analisys. Berlin, Springer Verlag, Dritter Band: v. III, p. 626-725, 1995.

[27] TASSOU, C. C.; DROSINOS, E. H.; NYCHAS, G. J. E. Inhibition of resident microbial flora and pathogen inocula on cold fresh fish fillests in olive oil, oregano, and lemon juice under modified atmosphere on air. J. Food Protection, Iowa, v. 59, n. 1, p. 31-34, 1995.

[28] THORNER, R.M.; REMEIN, Q.R. Principles and procedures in the evaluation of screening for diseases. Washington, U.S. Govt. Print. Off, Public Health Monograph, n 67, 24 p., 1961.

[29] WORLD HEALTH ORGANIZATION. Procedimientos para la investigación de bortes de enfermidades transmitidas por los alimentos. $2^{\text {nd }} \mathrm{ed}$. Washington, OPA/OMS, 1967.

\section{6 - AGRADECIMENTOS}

À Fundação de Amparo à Pesquisa do Rio Grande do Sul (Fapergs) e ao Conselho Nacional de Desenvolvimento Científico e Tecnológico (CNPq). 